\title{
Acute anemia after dental extraction: A case report
}

\author{
Stéphane Aïche ${ }^{1}$, Maria Pia Gandolfini ${ }^{2}$, Pascale Gaussem ${ }^{3,4,5}$, Alp Alantar ${ }^{6}$ \\ ${ }^{1}$ Oral Surgery Unit, Charles Foix Hospital, Ivry-sur-Seine, France \\ ${ }^{2}$ Cardiology Unit, Max Fourestier Hospital, Nanterre, France \\ ${ }^{3}$ Paris Descartes University, Sorbonne Paris Cite, Paris, France \\ ${ }^{4}$ AP-HP, Hôpital Européen Georges Pompidou, Hematology Department, Paris, France \\ ${ }^{5}$ InsermUMR-S765, Faculté de Pharmacie, Paris, France \\ ${ }^{6}$ Oral Surgery Unit, Max Fourestier Hospital, Nanterre, France \\ Email: alapalantar@wanadoo.fr
}

Received 6 January 2014; revised 7 February 2014; accepted 16 February 2014

Copyright (c) 2014 Stéphane Aïche et al. This is an open access article distributed under the Creative Commons Attribution License, which permits unrestricted use, distribution, and reproduction in any medium, provided the original work is properly cited. In accordance of the Creative Commons Attribution License all Copyrights (C) 2014 are reserved for SCIRP and the owner of the intellectual property Stéphane Aïche et al. All Copyright (C) 2014 are guarded by law and by SCIRP as a guardian.

\section{ABSTRACT}

A patient treated with a vitamin $K$ antagonist (VKA) since the implantation of two mechanical heart valves developed acute anemia after the extraction of a tooth. This case report and data in the literature indicate a need for specific measures before, during, and after oral surgery in patients taking anticoagulant therapy: 1) the bleeding risk should be evaluated before the procedure. The INR should be measured routinely, 2) the procedure should be scheduled early in the week to allow an evaluation at the fibrinolysis peak, i.e., 48 to 72 hours after surgery, which is the time of greatest risk of delayed bleeding, 3) the surgical procedure should be appropriate for the elevated bleeding risk, 4) postoperative monitoring is of the most importance, as bleeding is usually delayed in patients on VKA therapy, 5) when poor treatment adherence is expected, day-hospital admission is useful to ensure that the postoperative protocol is implemented properly and to detect early bleeding. The treatment of postextraction acute anemia includes local hemostasis protocol with the revision of the socket followed by red-blood-cell pack transfusion. A daily fluindione dosage control, and a normal hemoglobin level will allow the patient to leave the hospital.

\section{KEYWORDS}

Case Study; Oral Hemorrhage; Acute Anemia; Anti Coagulant Treatment; Extraction; Hemostasis

\section{INTRODUCTION}

Few data are available on acute anemia following dental extraction. Most of the reported cases occurred in patients with congenital coagulation disorders [1,2] or in patients receiving thrombosis prophylaxis, usually with vitamin $\mathrm{K}$ antagonists (VKAs). We suggest a therapeutic and preventive strategy for VKA-treated patients requiring oral surgery, based on our case of post-extraction acute anemia and on a literature review.

\section{CASE REPORT}

A 50-year-old woman from North Africa was referred on an emergency basis to the Oral Surgery Unit of the Max Fourestier hospital, Nanterre, France, for extraction of the left maxillary first molar, which was necrotic and exhibited extensive decay of the crown and roots. She had a history of biological valve implantation at 26 years of age for aortic and mitral disease. Degeneration of the biological valves required replacement by mechanical valves when she was 42 years of age. Bleeding from an ulcer in the duodenal bulb during the postoperative period led to partial gastrectomy. Thrombosis prophylaxis treatment with fluindione (Previscan ${ }^{\circledR} 20$-mg tablets) was initiated, with a target INR of 3 to 4.5 .

A few days before her arrival at our department, she had seen a dental surgeon in private practice for pain in tooth \#26. The oral surgeon diagnosed pulp necrosis due to mesial decay (Figure 1), opened the pulp cavity, irrigated it with sodium hypochlorite, prescribed amoxicillin ( 2 g/day for 6 days) given the high risk of endocarditis, and referred the patient to the hospital for extraction of the tooth.

At arrival in our Oral Surgery Unit, the last INR was 3.95, within the therapeutic target range. After discussion with the cardiologist, the surgeon decreased the fluindione dose by $25 \%$ to limit the hemorrhagic risk; sche- 


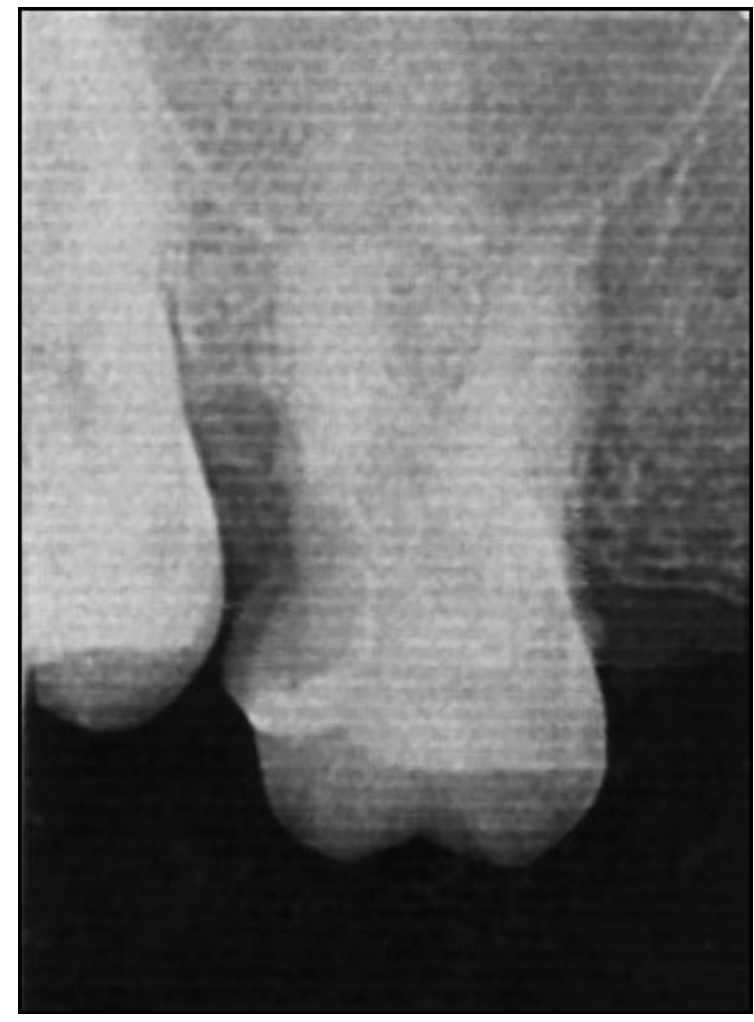

Figure 1. Initial retroalveolar radiograph.

duled the procedure for 48 hours later, at the end of the week, with a local hemostasis protocol; and prescribed a single oral dose of $3 \mathrm{~g}$ of amoxicillin/clavulanic acid to be taken 1 hour before the procedure [3]. On the day of the procedure, the INR was 3.16, which was within the desired range.

The surgical protocol involved local anesthesia, separation of the roots, removal of the tooth, curetting of the socket, implantation in the socket of absorbable oxidized cellulose (Surgicel $^{\circledR}$, Johnson \& Johnson, Neuchatel, Switzerland) impregnated with $10 \%$ tranexamic acid (Exacyl $^{\circledR}$, sanofi-aventis, France), suturing with absorbable polyglactin (Vicryl rapide ${ }^{\circledR}$ 3.0, Johnson \& Johnson), and implantation of Surgicel ${ }^{\circledR}$ mesh secured to the wound with tissue adhesive (Indermil ${ }^{\circledR}$ xfine, Henkel, Ireland).

Local hemostasis was achieved and checked 20 minutes after the end of the procedure. The discharge prescription was for therapeutic amoxicillin/clavulanic acid (2 g/d for 8 days), acetaminophen (40 mg/Kg/d), and gentle mouthwashes with $10 \%$ tranexamic acid (Exacyl ${ }^{\circledR}$, oral solution in vials, $1 \mathrm{~g} / 10 \mathrm{~mL}$ ) every 6 hours for 5 days. Fluindione (Previscan ${ }^{\circledR}$ ) therapy was returned to the usual daily dosage of $3 / 4$ of a tablet $(15 \mathrm{mg})$ on the evening of the procedure, with the agreement of the cardiologist. Written instructions and oral explanations for postoperative care were given to the patient.

At the follow-up visit 4 days later, the patient com- plained of severe asthenia and reported steady bleeding from the wound, for which she had not seen fit to seek medical advice. Extreme pallor of the skin and mucous membranes was noted. Healing was delayed because of persistent bleeding (Figure 2).

An emergency blood test showed severe anemia with a hemoglobin level of $6.8 \mathrm{~g} / \mathrm{dL}$. A mean corpuscular volume of $76 \mathrm{fl}$ (reference range: 80 - 100) and decreased ferritin level (13 $\mu \mathrm{g} / \mathrm{L}$, reference range: 15 - 150) was in accordance with an iron deficiency, probably related to previous bleeding episodes. The INR was abnormally high, at 5.5 .

Revision surgery was performed. The blood clot was removed, the socket was revised and filled with Surgi$\mathrm{cel}^{\circledR}$, new sutures were performed, and Surgicel ${ }^{\circledR}$ mesh was secured to the wound with tissue adhesive. A resin compression splint was fashioned on an emergency basis and placed in the mouth (Figure 3).

The patient was admitted to the cardiology unit, where she immediately received a red-blood-cell pack. The daily fluindione dosage was decreased by $25 \%$. The blood transfusion was effective, with a hemoglobin level of $8 \mathrm{~g} / \mathrm{dL}$.

On the next day, despite the aggressive local hemostasis protocol initiated after the revision procedure, the bleeding recurred. The socket was revised again and filled with Surgicel ${ }^{\circledR}$, sutures were performed, and a new Surgicel $^{\circledR}$ mesh was secured to the wound with tissue adhesive. The resin compression splint was secured with Coe-Pack ${ }^{\circledR}$ to improve stability (Figure 4).

Two additional red-blood-cell packs were given, which increased the hemoglobin level to $11.8 \mathrm{~g} / \mathrm{dL}$. Parenteral

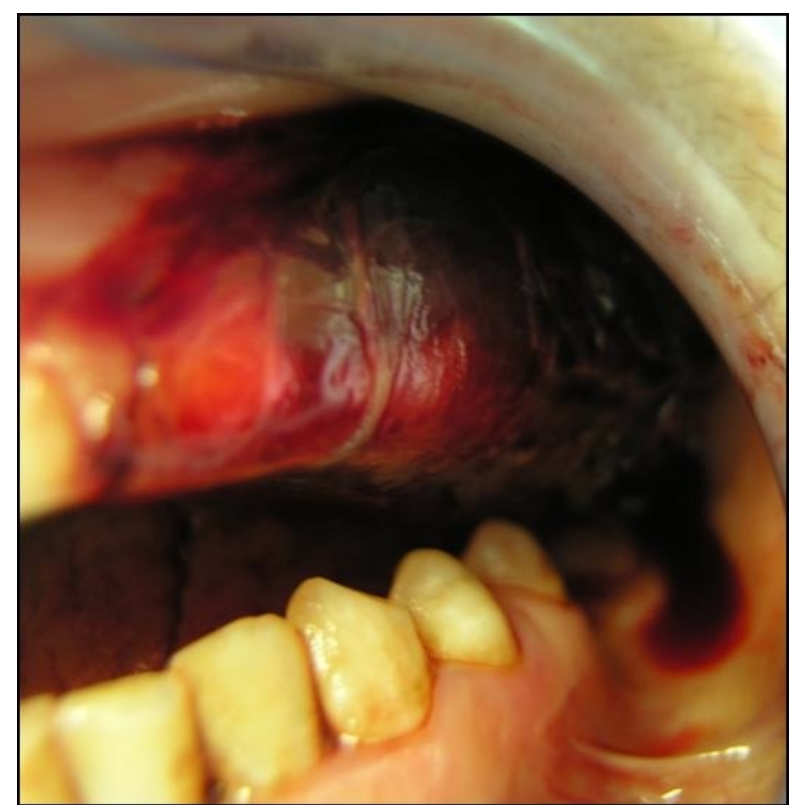

Figure 2. Bleeding after extraction in a patient taking vitamin $\mathrm{K}$ antagonist therapy. 


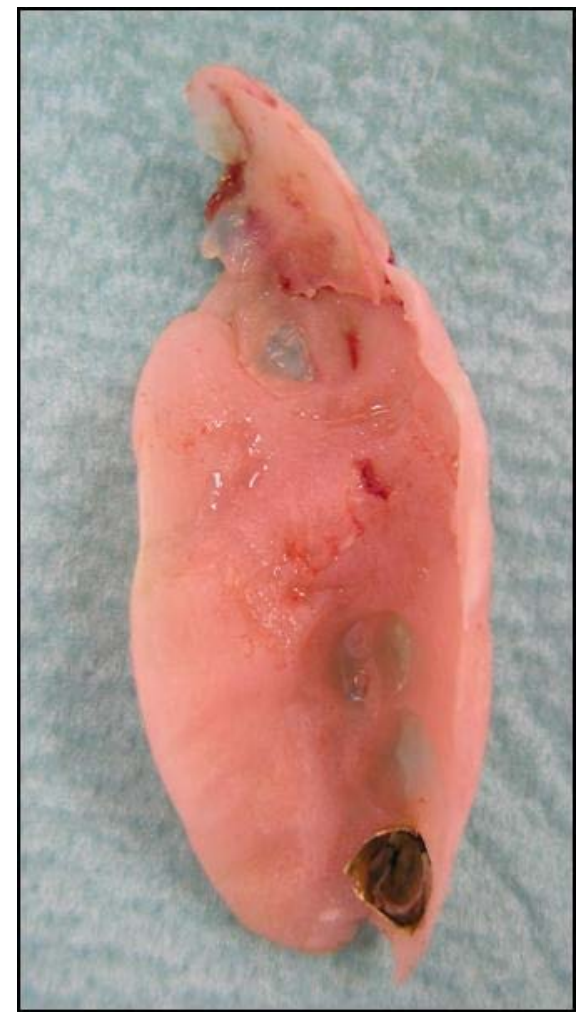

Figure 3. Resin hemostatic splint.

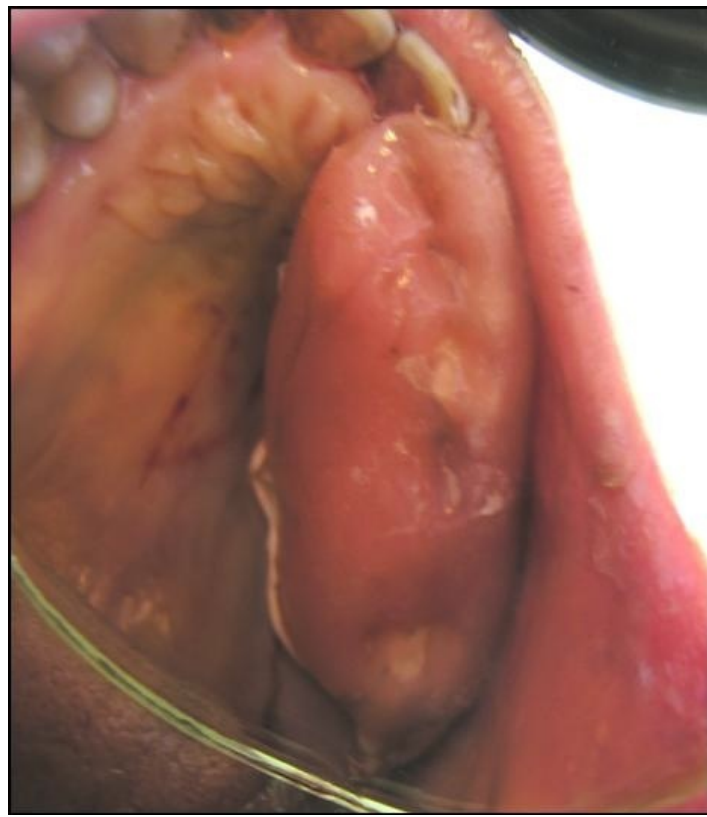

Figure 4. Resin hemostatic splint stabilized with CoePack $^{\circledR}$.

ferric hydroxide-saccharose (Venofer ${ }^{\circledR}$, Vifor France) was given, followed by oral ferrous sulfate-folic acid (Tardyferon B9 ${ }^{\circledR}$, Pierre Fabre, France).

On the next day, the patient reported feeling better and had no bleeding. Her hemoglobin level was stable at 11.8 $\mathrm{g} / \mathrm{dL}$. She was discharged after a total hospital stay of 10 days. Her anticoagulation was stable with a target INR of 3.0 to 4.5. The resin compression splint was removed 10 days after discharge. A clinical and radiological reevaluation 6 months later showed good healing of the bone and mucosa (Figures 5 and 6).

\section{DISCUSSIONS}

Few data are available on acute anemia following dental extraction. Most of the reported cases occurred in patients with congenital coagulation disorders [1,2] or in patients receiving thrombosis prophylaxis, usually with vitamin $\mathrm{K}$ antagonists (VKAs) [4]. Studies of the bleed-

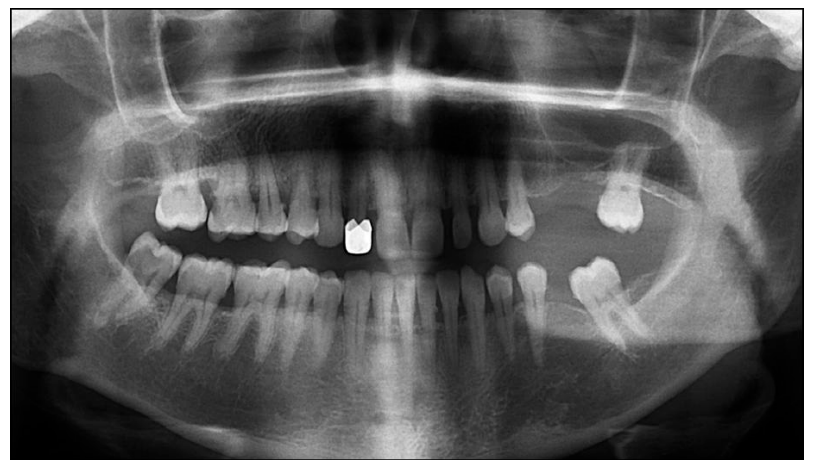

Figure 5. Panoramic radiograph obtained 6 months later.

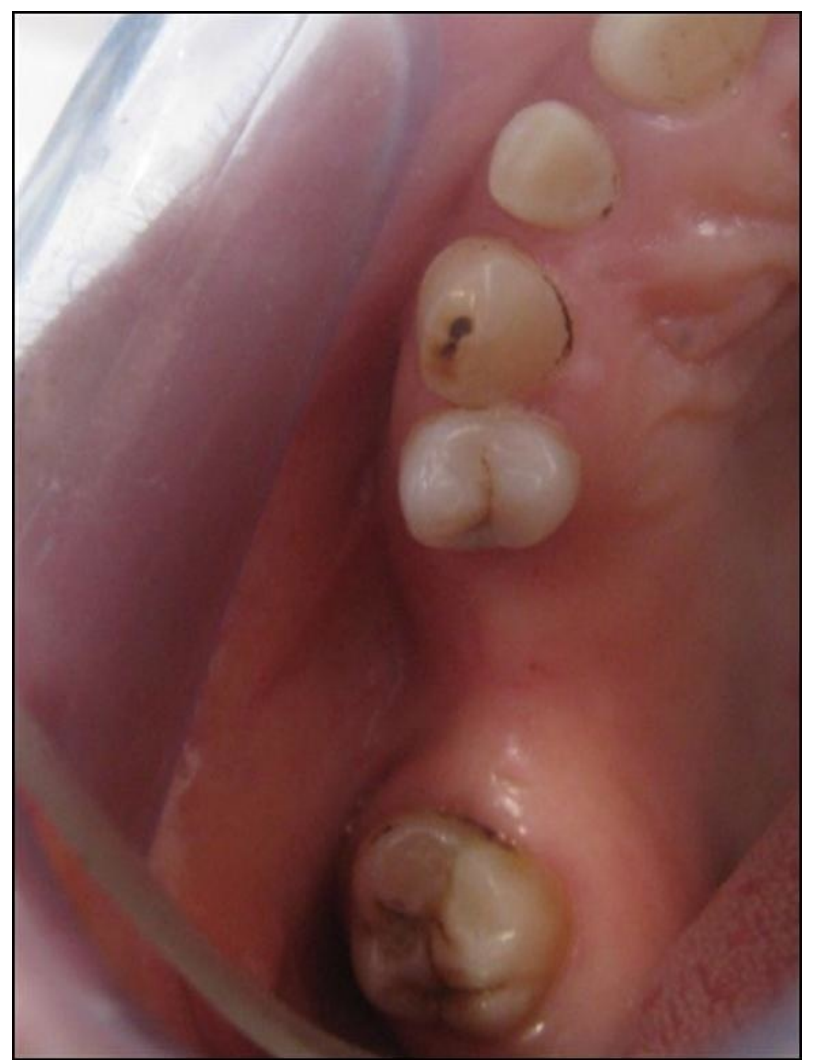

Figure 6. View from the lingual side 6 months after surgery. 
ing risk associated with oral surgery showed that a properly implemented local protocol was effective in ensuring hemostasis during surgery [5,6]. In contrast, an INR value greater than 2.5 was associated with an increased risk of delayed bleeding $[7,8]$, whose prevalence was estimated at about 10\% [9]. Available VKAs include the coumarin family (warfarin, acenocoumarol and phenprocoumon), and indandiones (fluindione). Fluindione is frequently used in middle-aged patients in France because of its shorter half-life compared to warfarin (31 h vs $36-42 \mathrm{~h}$ ). Fluindione also differs from warfarin as it is not metabolized by CYP2C9 enzyme of cytochrome P450 system.

In our patient, surgical trauma was minimized, granulation tissue was removed by painstaking curettage, and noncompressive oxidized cellulose $\left(\right.$ Surgicel $^{\circledR}$ ) impregnated with tranexamic acid $\left(\right.$ Exacyl $\left.^{\circledR}\right)$ was implanted into the socket. The wound was sutured and covered with Surgicel ${ }^{\circledR}$ mesh secured using tissue adhesive. Examination 20 minutes later showed no bleeding. Thus, the acute anemia was related to delayed bleeding, in keeping with previously published data [6].

Our patient had six risk factors for bleeding. 1) She had a history of major bleeding, consisting in duodenal bleeding after heart surgery. 2) The procedure had to be scheduled on an emergency basis, to alleviate the symptoms, and was performed at the end of the week. She was given a follow-up appointment for the next Tuesday, but the bleeding started over the weekend, when our odontology department was closed. In addition, the patient underestimated the significance of the bleeding and did not comply with the postoperative care instructions, as she did not seek help before her scheduled appointment. 3) Tooth \#26 is an antral tooth. The retroalveolar radiograph in our patient clearly showed the proximity of the tooth apex with the floor of the sinus (Figure 1). Disruption of the sinus mucosa can increase the risk of bleeding. 4) VKA therapy is associated with a high risk of postoperative bleeding and, more specifically, with the occurrence of delayed bleeding carrying a risk of potentially severe anemia [6]. In addition, our patient had a very high risk of thrombosis related to the presence of two mechanical heart valves and atrial fibrillation, requiring a high level of anticoagulation with a target INR of 3 to 4.5, compared to 2 - 3 in most other indications for VKA therapy. 5) Antibiotic therapy with amoxicillin-clavulanic acid was started at the end of the surgical procedure. An interaction between this antibiotic and fluindione explains the INR elevation to 5.5, which increased the risk of bleeding [10]. The interaction between VKA and antibiotics mostly results from the destruction of intestinal bacteria producing vitamin $\mathrm{K}$. It is not specific of fluindione but concerns all VKA molecules. Each INR point above 4 doubles the bleeding risk, which was therefore increased 3-fold in our patient [11]. 6) Finally, our patient failed to seek advice before her scheduled appointment, despite persistent bleeding for several days and, consequently, was not able to receive early treatment.

Our case report and data in the literature indicate a need for specific measures before, during, and after oral surgery in patients taking anticoagulant therapy.

First, the bleeding risk should be evaluated before the procedure. An important step is a review of the medical and surgical history including any past bleeding episodes and procedures. The postoperative course after previous surgical procedures provides guidance about the required aggressiveness of the hemostasis protocol. The INR should be measured routinely, and the appropriateness of diminishing the VKA dosage should be discussed with the cardiologist. Finally, the anatomic location of the surgical site is crucial to consider. Computed tomography should be performed if the tooth is near a structure likely to cause bleeding, such as the maxillary sinus, mandibular canal, or tuberosity. If this preoperative evaluation indicates an elevated bleeding risk, an aggressive hemostasis protocol should be used including a hemostatic splint, which can be stabilized during the procedure. In addition, day-hospital admission is indicated when poor treatment adherence is expected and/or the patient lives far from the hospital.

Second, the procedure should be scheduled early in the week to allow an evaluation at the fibrinolysis peak, i.e., 48 to 72 hours after surgery, which is the time of greatest risk of delayed bleeding [12].

Third, the surgical procedure should be appropriate for the elevated bleeding risk. Invasiveness should be minimized to spare the alveolar processes, which ensure stability of the clot. For teeth with multiple roots, root separation is preferable. Sparing the mucogingival junction during full-thickness detachment limits the size of the hematoma. Granulation tissue increases the risk of surgical site infection and bleeding and should be completely removed by careful curettage of the socket. The full hemostatic protocol includes noncompressive implantation of hemostatic material into the socket, effective suturing, oxidized cellulose secured over the wound, and use of a hemostatic splint.

Fourth, postoperative monitoring is of the utmost importance, as bleeding is usually delayed in patients on VKA therapy. The postoperative treatments must be described in detail and explained to the patient, family, and healthcare professionals (e.g., nurse or nursing assistant). An antifibrinolytic agent (tranexamic acid, Exacyl ${ }^{\circledR}$ ) is used as gentle mouthwashes three times daily for 5 days [5] and as compression packs in the event of bleeding [13-15]. Selection of the antibiotics and analgesics should take into account the many interactions between 
these two families of drugs and VKAs. In patients on VKA therapy, nonsteroidal antiinflammatory agents should be avoided and administration of amoxicillin/ clavulanic acid, similar to all other antibiotics, requires close monitoring of INR values [10,16-18]. Alternatively, amoxicillin alone or pristinamycin can be used. Detailed instructions about postoperative care should be given to the patient orally and in writing. When there is a language barrier, help should be sought from an interpreter, for instance a family member. Optimal treatment adherence is crucial to successful treatment and can be obtained only if the patient understands the postoperative regimen and its importance. An emergency telephone number should be communicated to the patient.

Fifth, when poor treatment adherence is expected, dayhospital admission is useful to ensure that the postoperative protocol is implemented properly and to detect early bleeding.

Strict compliance with these rules should increase the success rate of oral surgery procedures by avoiding complications that may be threatening and/or induce severe quality-of-life impairments.

\section{ACKNOWLEDGEMENTS}

The authors thank Pr. Louis Maman and Dr. Anne-Laure Ejeil for their contribution to this paper.

\section{REFERENCES}

[1] Correa, M.E. (2006) Clinical impact of oral health indexes in dental extraction of hemophilic patients. Journal of Oral and Maxillofacial Surgery, 64, 785-788. http://dx.doi.org/10.1016/j.joms.2005.11.044

[2] Heiland, M., Weber, M. and Schmelzle R. (2003) Lifethreatening bleeding after dental extraction in a hemophilia A patient with inhibitors to factor VIII: A case report. Journal of Oral and Maxillofacial Surgery, 61, 13501353. http://dx.doi.org/10.1016/S0278-2391(03)00739-0

[3] Agence Française de Sécurité Sanitaire des Produits de Santé (Afssaps) (2011) Prescription des antibiotiques en pratique bucco-dentaire. Recommandations. http://ansm.sante.fr/var/ansm_site/storage/original/applic ation/9d56ce8171a4a370b3db47e702eab17f.pdf

[4] Ziffer, A.M., Scopp, I.W., Beck, J., Baum, J. and Berger, A.R. (1957) Profound bleeding after dental extractions during dicumarol therapy. New England Journal of Medicine, 256, 351-353.

http://dx.doi.org/10.1056/NEJM195702212560806

[5] Blinder, D., Manor, Y., Martinowitz, U., Taicher, S. and Hashomer, T. (1999) Dental extractions in patients maintained on continued oral anticoagulant. Oral Surgery, Oral Medicine, Oral Pathology, Oral Radiology, and Endodontology, 88, 137-140.

[6] Bailey, B.M. and Fordyce, A.M. (1983) Complications of dental extractions in patients receiving warfarin anticoagulant therapy. A controlled clinical trial. British Dental
Journal, 155, 308-310.

http://dx.doi.org/10.1038/sj.bdj.4805221

[7] Devani, P., Lavery, K.M. and Howell, C.J. (1998) Dental extractions in patients on warfarin: Is alteration of anticoagulant regime necessary? British Journal of Oral and Maxillofacial Surgery, 36, 107-111.

http://dx.doi.org/10.1016/S0266-4356(98)90177-2

[8] Evans, I.L., Sayers, M.S., Gibbons, A.J., Price, G., Snooks, H. and Sugar, A.W. (2002) Can warfarin be continued during dental extraction? Results of randomized controlled trial. British Journal of Oral and Maxillofacial Surgery, 40, 248-252.

http://dx.doi.org/10.1054/bjom.2001.0773

[9] Salam, S., Yusuf, H. and Misosevic, A. (2007) Bleeding after dental extractions in patients taking warfarin. British Journal of Oral and Maxillofacial Surgery, 45, 463-466. http://dx.doi.org/10.1016/j.bjoms.2006.12.004

[10] Zhang, Q. (2011) Amoxicillin/clavulanic acid-warfarin drug interaction: A randomized controlled trial. British Journal of Clinical Pharmacology, 71, 232-236. http://dx.doi.org/10.1111/j.1365-2125.2010.03824.x

[11] Schulman, S., Beyth, R.J., Kearon, C. and Levine, M.N. (American College of Chest Physicians) (2008) Hemorrhagic complications of anticoagulant and thrombolytic treatment: American College of Chest Physicians Evidence-Based Clinical Practice Guidelines (8th Edition). Chest, 133, 257-298.

[12] Morimoto, Y., Niwa, H. and Minematsu, K. (2011) Risk factors affecting postoperative hemorrhage after tooth extraction in patients receiving oral antithrombotic therapy. Journal of Oral and Maxillofacial Surgery, 69, 15501556. http://dx.doi.org/10.1016/j.joms.2010.10.018

[13] Street, A.M. and Leung, W. (1990) Use of tranexamic acid mouthwash in dental procedures in patients taking oral anticoagulants. Medical Journal of Australia, 153, 630.

[14] Borea, G., Montebugnoli, L., Capuzzi, P. and Magelli, C. (1993) Tranexamic acid as a mouthwash in anticoagulant-treated patients undergoing oral surgery. An alternative method to discontinuing anticoagulant therapy. Oral Surgery, Oral Medicine, Oral Pathology, Oral Radiology, and Endodontology, 75, 29-31. http://dx.doi.org/10.1016/0030-4220(93)90401-O

[15] Gaspar, R., Brenner, B., Ardekian, L., Peled, M. and Laufer, D. (1997) Use of tranexamic acid mouthwash to prevent postoperative bleeding in oral surgery patients on oral anticoagulant medication. Quintessence International, 28, 375-379.

[16] Lane, M.A., Devinet, S.T. and McDonald, J.R. (2012) High-risk antimicrobial prescriptions among ambulatory patients on warfarin. Journal of Clinical Pharmacy and Therapeutics, 37, 157-160. http://dx.doi.org/10.1111/j.1365-2710.2011.01270.x

[17] Zhang, Q. (2011) Interaction between acetaminophen and warfarin in adults receiving long-term oral anticoagulants: a randomized controlled trial. European Journal of Clinical Pharmacology, 67, 309-314. http://dx.doi.org/10.1007/s00228-010-0975-2 
[18] Hatzis, G.P. (2013) Protocol for the management of oral surgery patients on warfarin utilizing a Point-of-Care inoffice international normalized ratio monitoring device.
Open Journal of Stomatology, 3, 255-267. http://dx.doi.org/10.4236/ojst.2013.34044 